\section{Adams-Oliver syndrome: a case with full expression}

Amir Dehdashtian, Masoud Dehdashtian

Ahvaz Jundishapur University of Medical Sciences, Iran

\section{Abstract}

Adams-Oliver syndrome (AOS) is characterized by the combination of congenital scalp defects (aplasia cutis congenita) and terminal transverse limb defects of variable severity. It is believed that Adams-Oliver syndrome without major organ abnormalities does not necessarily alter the normal lifespan. We present a case without detectable major organ abnormality contrary to life but with poor weight gain. A male infant with scalp and skin cutis aplasia, generalized cutis aplasia, dilated veins over scalp and trunk, hypoplastic toes and nails of feet, glaucoma, poor feeding and poor weight gain. This report shows a case of AOS without major multiple organ abnormalities but with poor feeding and abnormal weight gain that may be alter the normal lifespan.

\section{Introduction}

Adams-Oliver syndrome (AOS) is characterized by the combination of congenital scalp defects (aplasia cutis congenita) and terminal transverse limb defects of variable severity.

Since its original description, many reports have highlighted the variable expression of this condition.1,2 Cutis marmorata telangiectatica congenita is a relatively frequent feature. ${ }^{3}$ It is an autosomal dominant trait with highly variable penetrance and expression. Several isolated cases have been reported. Subsequently, it was reported that some cases of Adams-Oliver syndrome appear to have autosomal recessive inheritance, perhaps with somewhat more severe phenotypic effects. ${ }^{4}$ Dilated veins are frequently associated and may be the sole abnormality. ${ }^{4}$ Hypoplastic or absent distal phalanges are the most common limb anomalies, but defects range from hypoplastic nails to absent hands or lower legs. ${ }^{5}$ Here we report a case of AOS associated with significant cutaneous phlebectasia.

\section{Case Report}

A 40 days old male infant was referred to our clinic at Imam Khomeini hospital of Ahvaz
(Ahvaz Jundishapur University of Medical Sciences, Iran) for cutaneous lesions and poor weight gain. The infant's parents complain poor feeding and vomiting. He was delivered at term by vaginal delivery after a normal pregnancy. Apgar scores were 8 at 1 minute and 9 at 5 minutes. The child was born at 38 -week gestational age with a birth body weight of $1700 \mathrm{~g}$, a birth length of $47 \mathrm{~cm}$ and a head circumference of $32.5 \mathrm{~cm}$. No resuscitation was required after birth. His 24 years old mother had one previous pregnancy. The first child was healthy. The parents were healthy and cousins. The only drug used during pregnancy was multivitamin. Body weight was $1900 \mathrm{~g}$. The anterior fontanel measured $2.5 \times 2 \mathrm{~cm}$ and had a multiple vertex defect (Figure 1). The distal phalanges and nails of both feet were hypoplastic (Figure 2). The fingers of hands were normal. In examination of skin, generalized cutis marmorata was seen (Figure 3). Dilated veins were seen over trunk and head (Figure 4). The patient was formula fed. Abdominal sonogram was negative for hypertrophic pyloric stenosis. Liver and renal function test was normal. Serum electrolyte and arterial blood gases were normal. Echocardiogram was normal. Regular formula was substituted with hydrolyzed formula. Vomiting subsides, but poor feeding and poor weight gain continued. Body weight at 2 months age was $2200 \mathrm{~g}$. Ophthalmologic examination revealed left eye glaucoma.

\section{Discussion}

Adams-Oliver syndrome, which defined by the combination of limb abnormalities and scalp defects, was initially described in 1945 by Adams and Oliver. ${ }^{6}$ It is mostly inherited as an autosomal dominant (AD) trait, but also a suggestive autosomal recessive (AR) mode of inheritance and sporadic cases have been described. ${ }^{7}$ Our patient had no family history of congenital deformities of the scalp or extremities. The exact pathogenesis of AOS is unknown. Vascular impairment during embryogenesis has been proposed as a possible mechanism by several authors. Hoyme $e t$ $a l .{ }^{8}$ reported that the placentas villous vessels of patients with AOS contained multiple organized thrombi. They hypothesized that in-utero vascular thrombotic accident led to interruption of blood supply to developing structures. Other reports suggested that AOS is the result of the thrombotic interruption of blood supply in the subclavian, vertebral or other arteries through embryonic period. 9

Swartz and colleagues suggested that the abnormalities in AOS developed because of a generalized abnormality in small vessels causing disruption of blood flow. 10 Interruption of
Correspondence: Masoud Dehdashtian, Imam Khomeini Hospital, Azadegan st, Ahvaz, Iran. Tel.: +89.916.6117204 - Fax: +89.613.2216503. E-mail: dehdashtian@ajums.ac.ir

Key words: Adams-Oliver syndrome; absence defect of limbs; Cutis marmorata telangiectatica congenital; glaucoma.

Contributions: $\mathrm{MD}$, collection of data, discussion and final revision; $\mathrm{AD}$, wrote first draft of article.

Conflict of interest: the authors declare no potential conflict of interest.

Received for publication: 22 March 2015. Accepted for publication: 23 May 2015.

This work is licensed under a Creative Commons Attribution NonCommercial 4.0 License (CC BY-NC 4.0).

(C) Copyright A. Dehdashtian and M. Dehdashtian, 2016 Licensee PAGEPress, Italy

Pediatric Reports 2016; 8:6517

doi:10.4081/pr.2016.6517

blood flow through small arteries would account for the aplasia cutis congenita, terminal transverse limb defects, as well as the cardiac, hepatic, and pulmonary vascular lesions. Decreased stability of embryonic blood vessels toward tensile forces during the period of 6 to 8 th week of embryonic life due to a gene defect may explain the pathogenesis of vascular anomaly in AOS.11 Patel and colleagues suggested that abnormal pericyte recruitment to blood vessels may be a possible etiology. 12 The most frequently observed limb malformations in this disorder include syndactyly, brachydactyly, polydactyly, oligodactyly and hypoplastic finger/toenails. There is a great variability in severity of clinical manifestation ranging from the complete absence of the foot or hand to only mild manifestations or normal appearance, as seen in obligate AOS carriers. ${ }^{13}$ Aplasia cutis congenita are most frequently found on the vertex of the skull with variable depth and size. Skull defects underlying the scalp lesions may be found. ${ }^{14}$ Other associated defects with AOS include cutis marmorata telangiectasia congenita. Cutis marmorata telangiectatica congenita was found in $25 \%$ of reported cases and often involve the entire skin including the scalp. ${ }^{15-17}$ Ulceration related to particularly large dilated vessels in the skin, as occurred in our patient, is a recognized complication of cutis marmorata telangiectatica. 18 Prominent cutaneous and subcutaneous atrophy and linear depressions overlying dilated vessels on the chest and abdomen has been described previously. ${ }^{19}$ Terminal transverse limb defects associated with cutis marmorata telangiectatica without aplasia cutis congenita 


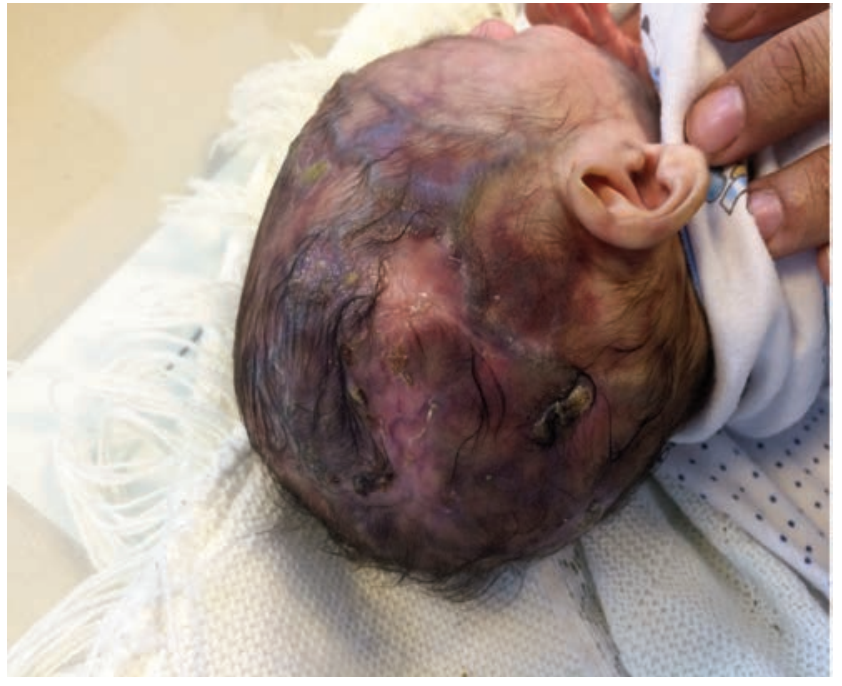

Figure 1. Multiple vertex skin defect and dilated veins.

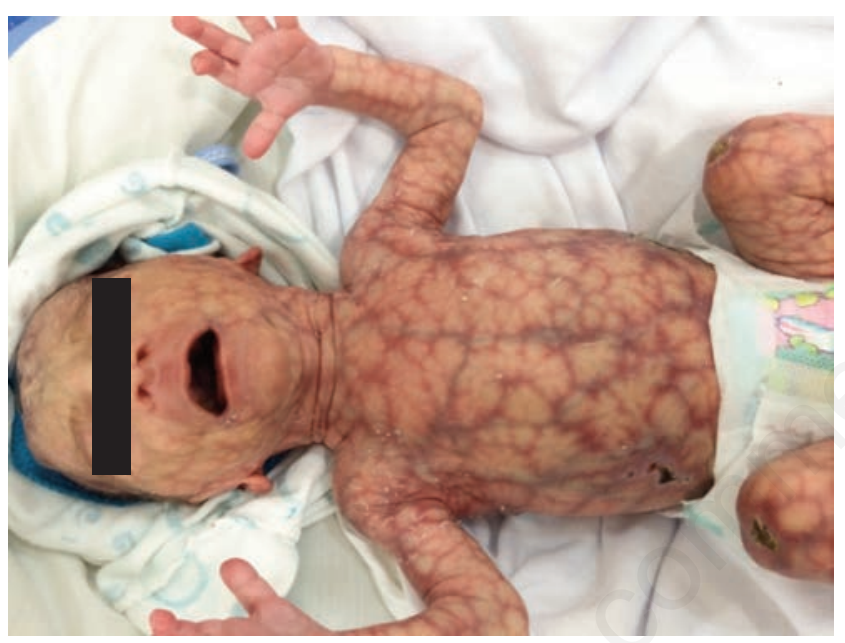

Figure 3. Generalized cutis marmorata.

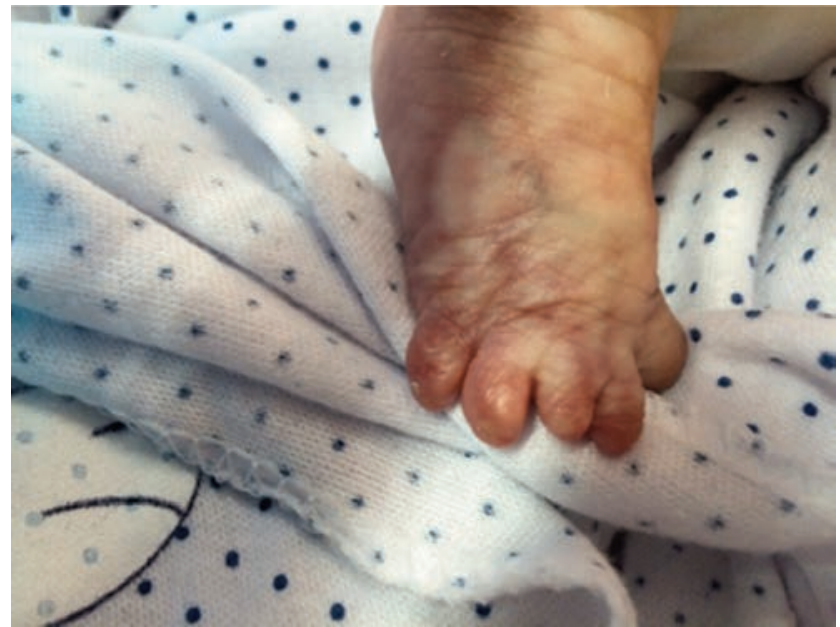

Figure 2. Hypoplastic fingers and nails.

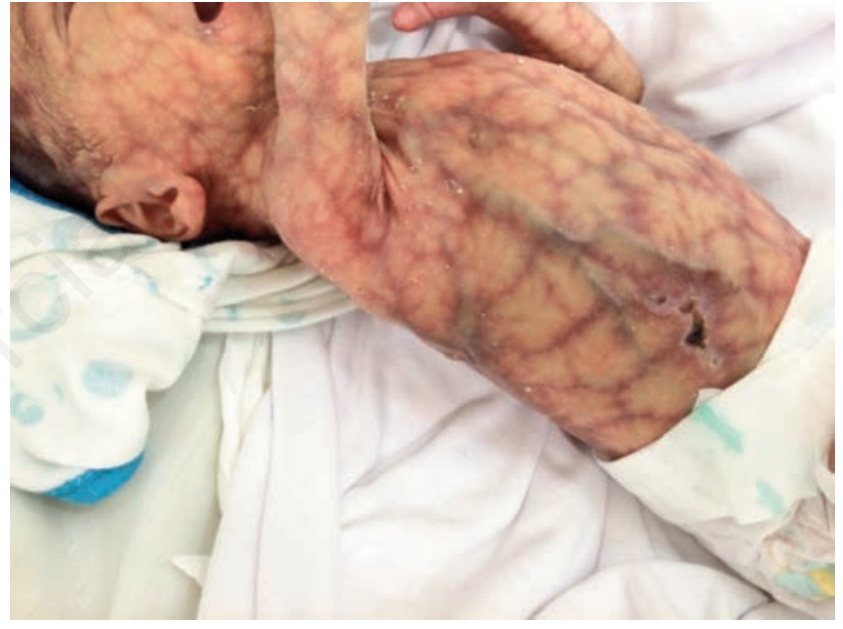

Figure 4. Dilated veins and skin ulcers.

\section{has been described.20}

Terminal transverse limb defects significantly affect the distal phalanges or entire digits. Both lower and upper limb defects can be seen, but lower limb defects are more common. Shortening of the fingers with loss of the terminal phalanges of the foot is the most common defect. 4

\section{Conclusions}

Various expressions of AOS have been reported. This report shows a case of AOS without major multiple organ abnormalities but with poor feeding and abnormal weight gain that may alter the normal lifespan.

\section{References}

1. Bakry 0, Attia A, El Shafey EN. AdamsOliver Syndrome. A case with isolated aplasia cutis congenita and skeletal defects. J Dermatol Case Rep 2012;6:25-8.

2. Pereira-Da-Silva L, Leal F, Santos GC, et al. Clinical evidence of vascular abnormalities at birth in Adams-Oliver syndrome: report of two further cases. Am J Med Genet 2000;94:75-6.

3. Kuster W, Lenz W, Kaariainen H, Majewski F. Congenital scalp defects with distal limb anomalies (Adams-Oliver syndrome): report of 10 cases and review of the literature. Am J Med Genetics 1988;31:99-115.

4. Kutlubay Z, Pehlivan 0. Adams-Oliver syn- drome. Int J Dermatol 2014;53:352-4.

5. See JK, Kang JH, Lee D, Hwang SW. A case of Adams-Oliver syndrome. Ann Dermatol 2010;22:96-8.

6. Adams FH, Oliver CP. Hereditary deformities in man: due to arrested development. J Hered 1945;36:3-7.

7. McGoey RR, Lacassie Y. Adams-Oliver syndrome in siblings with central nervous system findings, epilepsy, and developmental delay: refining the features of a severe autosomal recessive variant. Am J Med Genet 2008;146:488-91.

8. Hoyme HE, Jones KL, Van Allen MI, et al. Vascular pathogenesis of transverse limb reduction defects. J Pediatr 1982;101:83943.

9. Fryns JP, Legius E, Demaerel P, van den 
Berghe H. Congenital scalp defect, distal limb reduction anomalies, right spastic hemiplegia and hypoplasia of the left arteri cerebri media: further evidence that interruption of early embryonic blood supply may result in Adams-Oliver (plus) syndrome. Clin Genet 1996;50:505-9.

10. Swartz EN, Sanatani S, Sandor GG, Schreiber RA. Vascular abnormalities in Adams-Oliver syndrome: cause or effect? Am J Med Genet 1999;82:49-52.

11. Pousti TJ, Bartlett RA. Adams-Oliver syndrome: genetics and associated anomalies of cutis aplasia. Plast Reconstr Surg 1997;100:1491-6.

12. Patel MS, Taylor GP, Bharya S, et al. Abnormal pericyte recruitment as a cause for pulmonary hypertension in Adams-
Oliver syndrome. Am J Med Genet A 2004;129A:294-9.

13. Sankhyan N, Kaushal RK, Jaswal RS. Adams-Oliver syndrome: a case with complete expression. J Dermatol 2006;33:4356.

14. Verdyck P, Holder-Espinasse M, Hul WV, Wuyts W. Clinical and molecular analysis of nine families with Adams-Oliver syndrome. Eur J Hum Genet 2003;11:457-63.

15. Atherton DJ, Moos C. Aplasia cutis congenita. In: Burns T, Breathnach S, Griffiths C, Cox N, eds. Rook's Textbook of Dermatology, 7th ed. 0xford: Blackwell Science; 2004: pp 667-75.

16. See JK, Kang JH, Lee D, Hwang SW. A case of Adams-Oliver syndrome. Ann Dermatol 2010;22:96-8.
17. Khashab YE, Nejat F, Fried A. Management of large scalp and skull defects in a severe case of Adams-Oliver syndrome. J Neurosurg Pediatr 2009;4:523-7.

18. Picascia DD, Esterly NB. Cutis marmorata telangiectatica congenita: report of 22 cases. J Amer Acad Dermatol 1989;20: 1098-104.

19. Frank RA, Frosch PJ. Adams-Oliver syndrome: cutis marmorata telangiectatica congenita with multiple anomalies. Dermatology 1993;187:205-8.

20. Bjornsdottir US, Laxdal T, Bjdrnsson J. Cutis marmorata telangiectatica congenita with terminal transverse limb defects. Acta Paediatr Scand 1988;77:780-2. 